\title{
Assessing Paternity in Japanese Quails (Coturnix Japonica) Using Microsatellite Markers - Inferences for Its Mating System and Reproductive Success
}

\section{-Author(s)}

Gomes ML

Hatanaka T"

Campos WN dell

Wasko APIN

PhD student, FAPESP grantee, Department of Genetics, Biosciences Institute, São Paulo State University (UNESP) - Botucatu, SP, Brazil. E-mail: gomes.magalilira@gmail.com

" PhD, Technician, Department of Genetics and Evolution, Federal University of São Carlos (UFSCar) - São Carlos, SP, Brazil. E-mail: hterumi@yahoo.com.br

III PhD student, CAPES grantee, Department of Genetics and Evolution, Federal University of São Carlos (UFSCar) - São Carlos, SP, Brazil. E-mail:wncampos@yahoo.com.br

Iv PhD, Assistant Professor, Department of Genetics, Biosciences Institute, São Paulo State University (UNESP) - Botucatu, SP, Brazil. E-mail: awasko@ibb.unesp.br

\section{Mail Adress}

Corresponding author e-mail address Adriane Pinto Wasko, UNESP -

Departamento de Genética, Instituto de Biociências, Universidade Estadual Paulista - UNESP, CEP 18618-970, Botucatu, São Paulo, Brazil. Phone: 55-14-38800364.

E-mail: awasko@ibb.unesp.br

\section{nKeywords}

Coturnix japonica, parentage testing, polyandry, quail, SSRs.

\section{ABSTRACT}

Microsatellite markers were analyzed in Japanese quails, Coturnix japonica, using different methodologies (PAGE and automated genotyping), in order to evaluate their use in paternity testing. Ten animal triplets composed by a female and two males were used to mate and generate an offspring. Paternity was determined in five-day-old embryos, and the data generated by fluorescent labeled and tailored primers in PCR and further automated genotyping were robust. Three microsatellite markers were polymorphic $\left(\mathrm{Na}=5-8, H_{E}=0.75\right)$ and no loci were found to deviate significantly from Hardy-Weinberg equilibrium or showed any evidence of linkage disequilibrium ( $p>0.05$ ). A slight heterozygote deficiency and some incompatibilities between the female known parent and its offspring that involved homozygous genotypes were observed at GUJ0001 locus and may indicate the presence of null alleles. Although a reduced set of microsatellite primers were applied, it was possible to determine the paternity of $96.87 \%$ of the embryos, using combined data of three loci. The approach was useful for parentage inferring in a captive population of $C$. japonica and the results evidenced a potential polyandric mating system in the species, in which no advantage mechanism of last-male sperm precedence seems to occur.

\section{INTRODUCTION}

The development of DNA-based markers has had a revolutionary impact on gene mapping and, more generally, on several other animal and plant genetics research data, such as measurement of gene flow and migration, assignment of individuals to their population of origin, measurement of effective population size, and detection of past demographic bottlenecks (Jehle \& Arntzen, 2002; Gholizadeh \& Mianji, 2007). Besides, the implement of the polymerase chain reaction (PCR) allowed the development and application of several DNA markers (Marle-Koster \& Nel, 2003). Microsatellites or SSRs (Simple Sequence Repeats) are now one of the most widely used molecular markers in several eukaryotic species, specially due to their relative ease of scoring and ability to exhibit high levels of polymorphism (Wolfgang et al. 2011). Several studies have revealed that microsatellites are not just useful in population analyses, but also suitable for the measurement of genetic parameters such as number of effective alleles ( $\mathrm{Ne}$ ) and rare alleles (Bartfai et al. 2003), and also for the characterization/identification of genetic alterations (Powierska-Czamy, 2003), and individual identification (Shurtliff, 2005). Today, microsatellites represent the most useful DNA markers in genotyping and paternity analyses (Webster \& Reichart, 2005; Shurtliff, 2005).

In birds, analyses using molecular markers specially modified the understanding of social and reproductive behavior, leading to the 
detection of extra-pair copulation in several species (Griffith et al,. 2002; Masters et al., 2003; Fossoy et al., 2006). As extra-pair fertilizations are common in birds, reliable assessment of paternity is essential. The excluding paternity tests in birds began through allozyme analyses and, later, minisatellite repeats were used for this purpose. Currently, microsatellites are the most widely used molecular markers to elucidate genetic relationships in different bird species (e.g. Alcaide et al., 2005). However, one of the main limitations of using these markers in birds refers to the reduced frequency of microsatellite repeats in this animal group, mainly at the sex chromosomes and microchromosomes (Primmer et al., 1997).

Microsatellite markers were recently isolated from the Japanese quail Coturnix japonica as an effort to contribute to the development of reference maps for this avian species, which were mainly obtained using microsatellite repeats of chicken (Pang et al., 1999; Kayang et al., 2000; Kayang et al., 2004; Kikuchi et al., 2005). The Japanese quail was first domesticated in Japan around the $15^{\text {th }}$ century as a pet song bird (Kovach, 1974). In addition of being reared for egg/ meat production, it is becoming increasingly used as an experimental research animal, due to several characteristics, such as its small body size, short generation interval, and high egg production (Pisenti et al., 1999). However, in contrast with chickens (Gallus gallus), little is known about the Japanese-quail genome. As paternity analyses were only performed in Japanese quail using multilocus DNA fingerprinting (Matthews et al., 2007), the goal of the present study was to implement a paternity test analysis for this species by performing a multiple mating strategy and genotyping of adult males and females and their offspring using microsatellite markers. The generated data were used to support behavioral analyses of this species.

\section{MATERIAL AND METHODS Animal samples}

The Ethical Commitee on Animal Experimentation (CCEA) of the Biosciences Institute of UNESP approved this study with Japanese quails (Coturnix japonica; Galliformes, Phasianidae) under protocol number 42/05.

Two-day-old individuals were obtained from a private farm (Granja Suzuki, São Paulo, SP, Brazil) and maintained in cages at maximum density of 141 birds $/ \mathrm{m}^{2}$, as suggested by SEBRAE (Serviço Brasileiro de Apoio às Micro e Pequenas Empresas de São Paulo, 2005). During the first month, birds were fed a grower feed with $24 \%$ crude protein and 2,900 kcal metabolizable energy $(\mathrm{ME}) / \mathrm{kg}$. Feed and water were supplied ad libitum. Environmental temperature was maintained at $37-39^{\circ} \mathrm{C}$ during the first week and it was further reduced to $25^{\circ} \mathrm{C}$ during the three subsequent weeks. Birds were transferred to individual cages (16 $\times 24 \times 18 \mathrm{~cm}$ ) at approximately 45 days of age, and were fed a commercial feed (Purina) with higher calcium (3.5 to $4.0 \%$ ) and lower protein (20 to $22 \%$ ) contents than the previous feed and 2,900 kcal ME/kg. Temperature was maintained at $20-25^{\circ} \mathrm{C}$ temperature and a photoperiod of 14 hours of light/10 hours of dark was applied.

\section{Bird selection and sexual interaction}

Adult females and males (older than 45 days), presenting regular lay and prominent cloacal gland, respectively, and that had previous sexual experience were chosen to compose 10 groups (ten triplets, each composed by a female and two males). In order to maintain the sexual dimorphism of the species, in each group, the female was heavier than the males, and the two males presented a similar weight. In order to correctly identify the males in each group, one bird was marked in the legs.

A behavioral analysis was performed during the period when the birds' sexual behavior frequency is higher (between 14:30 and 17:30 pm; Delville et al., 1986), using a specific cage made of transparent acrylic. The cage, consisting of a central area and two lateral compartments of acrylic walls (adapted from White \& Galef, 1999), was used in order to maintain the three animals separated during 1 minute - the female in the central area and each of the two males in one of the lateral compartments. After this short adaptation period, the acrylic walls of the lateral compartments were removed, and the three birds were allowed to interact for 15 minutes. The number of copulations of each male was recorded. After the behavioral analysis, birds were separated and the eggs of each female were collected from the first day until the $12^{\text {th }}$ day of the behavioral experiment and maintained in an electric incubator at $37.5^{\circ} \mathrm{C}$ and relative humidity of $50-70 \%$ during 5 days.

\section{Dna isolation and amplification}

Genomic DNA was extracted from $800 \mu \mathrm{L}$ of blood collected from the brachial vein of the adult animals and of 5-day-old embryos generated by the eggs of 
each female, using a TNES digestion buffer and phenolchloroform, as detailed in Sambrook \& Russel (2001). The extraction procedure was performed twice in order to ensure good-quality DNA. DNA integrity and quantity was checked on $1 \%$ agarose gel by direct comparison with a standard marker (Low DNA Mass Ladder Gibco.Brl) using the software program Stratagene EagleSight v. 3.22, and in a spectrophotometer (Nano Drop ND-1000 Spectrophotometer - Thermo Fisher Scientific). Five primer sets specific to microsatellite loci of different repetitions, originated from Coturnix japonica (Kayang et al., 2000) (Table 1), were initially tested using the DNA samples of some adult individuals in order to test the effect of DNA, $\mathrm{MgCl}_{2}$, primers, and Taq DNA polymerase concentrations, to determine the optimum annealing temperature, and to optimize the reproducibility of the PCR assays. Further DNA amplifications using two different methodologies were carried out for all adult individuals for each experimental group and in their generated embryos. Subsequently, a PAGE (Polyacrylamide Gel Electrophoresis) and an automated genotyping analysis were performed. All birds were genotyped at least three times by each methodology, using independent PCR amplifications to avoid genotyping errors.

\section{Microsatellite loci amplification with common primers and page genotyping}

Each $P C R$ reaction mixture consisted of $1 \mathrm{x}$ reaction buffer (10mM Tris- $\mathrm{HCl} \mathrm{pH} 8.0,50 \mathrm{mM} \mathrm{KCl}, 1.5 \mathrm{mM}$ $\mathrm{MgCl}_{2}$ - USB), $1.25 \mathrm{mM}$ of each dNTP (Invitrogen), $5 \mu \mathrm{M}$ of forward and $5 \mu \mathrm{M}$ of reverse primer (Table 1), 50ng of genomic target DNA, and $1.25 \mathrm{U}$ of Taq DNA polymerase (USB), in a total volume of $25 \mu \mathrm{L}$. Amplifications were carried out in a Mastercycler Personal thermocycler (Eppendorf) with the following cycle program: a first denaturation step at $94^{\circ} \mathrm{C}$ for 5 min, followed by 30 cycles of $94^{\circ} \mathrm{C}$ for $30 \mathrm{~s}, 55-65^{\circ} \mathrm{C}$ for $1 \mathrm{~min}$ (Table 1), and $72^{\circ} \mathrm{C}$ for $1 \mathrm{~min}$, and a final extension step at $72^{\circ} \mathrm{C}$ for $5 \mathrm{~min}$. A negative control, consisting of all the reaction components, except for the template DNA, was also included to monitor any possible contamination. Reactions products ( 6 $\mu \mathrm{L}$ ) were subjected to $6 \%$ and $8 \%$ non-denaturing polyacrylamide gel electrophoresis for approximately 6 hours at 120V. DNA bands were visualized after Ag-nitrate staining (Sambrook and Russel 2001) and molecular weights were estimated using standard DNA markers (10 bp DNA and 1 Kb DNA Ladders Invitrogen). The photo-documentation was performed under white light (Hoefer UV-25) using the computer program Strategene EagleSight v. 3.22 (Stratagene).

\section{Microsatellite loci amplification using labeled primers and automated genotyping}

The same five sets of primers (Table 1) were also applied in the DNA samples using the protocol described by Schuelke (2000). A tail (5'-TGT AAA ACG ACG GCC AGT-3' (M13(-21)) was added to each forward primer and universal primers M13(-21) were labeled with the fluorescent compounds FAM (6-carboxy-fluorescein), NED (naptiletilenediamine dihydrochloride) or HEX (hexacloro-6-carboxy fluorescein). Each PCR reaction mixture consisted of $1 x$ reaction buffer $(10 \mathrm{mM}$ Tris$\mathrm{HCl} \mathrm{pH} \mathrm{8.0,50mM} \mathrm{KCl,} 1.5 \mathrm{mM} \mathrm{MgCl}$ - USB), $0.4 \mu \mathrm{L}$ of dNTPs $(2.5 \mathrm{mM}), 0.5 \mu \mathrm{L}$ of reverse primer (8pmol/ $\mathrm{ml}), 0.5 \mu \mathrm{L}$ of $\mathrm{M} 13(-21)$ primer $(8 \mathrm{pmol} / \mathrm{ml})$ labeled with one of the fluorescent compounds, $0.5 \mu \mathrm{L}$ of forward primer with the tail $(2 \mathrm{pmol} / \mathrm{ml}), 0.2 \mu \mathrm{L}$ of $\mathrm{MgCl}_{2}(50 \mathrm{Mm})$, 50ng of genomic target DNA, and 1.25U Taq DNA polymerase (USB), in a total volume of $10 \mu \mathrm{L}$. Amplifications were carried out in a gradient

Table 1 - Microsatellite loci characterization of Coturnix japonica.

\begin{tabular}{|c|c|c|c|c|c|c|c|c|c|}
\hline Locus & Repeat motif & Primer sequence $\left(5^{\prime}-3^{\prime}\right)$ & $N$ & $\mathrm{Na}$ & $\mathrm{Ta}\left({ }^{\circ} \mathrm{C}\right)$ & allele size (bp) & $H_{0}$ & $H_{E}$ & Reference \\
\hline \multirow[t]{2}{*}{ GUJ0001 } & $(\mathrm{CA})_{7} \mathrm{TG}(\mathrm{CA})_{13}$ & F: GAAGCGAAAGCCGAGCCA & 90 & 5 & 65 & $247-255$ & 0.61 & 0.73 & present data \\
\hline & & R: CAGCACTTCGGAGCACAGGA & & & & & & & \\
\hline \multirow[t]{2}{*}{ GUJ0006 } & $(\mathrm{CA})_{14}$ & F: TGGGATGATAATGAGGTACGG & 88 & 8 & 55 & 127-139 & 0.82 & 0.81 & present data \\
\hline & & R: AGGATAGCATTTCAGTCACGG & & & & & & & \\
\hline \multirow[t]{2}{*}{ GUJ0025 } & $(\mathrm{CA})_{9}$ & F: CCTGAGCGAATACACAACTG & - & - & 60 & 245 & - & - & Kayang et al. (2000) \\
\hline & & R: AGTGTTAGGTGAGGACTGCT & & & & & & & \\
\hline \multirow[t]{2}{*}{ GUJ0030 } & $(C A)_{31}$ & F: TGCACCAATCCCAGCTGTTT & - & - & 64 & 181 & - & - & Kayang et al. (2000) \\
\hline & & R: AACGCACAATGGAAAGTGGG & & & & & & & \\
\hline \multirow[t]{2}{*}{ GUJ0037 } & $(\mathrm{CA})_{10} \mathrm{C}(\mathrm{CA})_{2}$ & F: CCATTCCTCCATCGTTCTGA & 92 & 8 & 55 & $190-206$ & 0.63 & 0.71 & present data \\
\hline & & R: GGGAAGGAGTGTAGGAAAGA & & & & & & & \\
\hline
\end{tabular}

$\mathrm{N}$, number of genotyped individuals; $\mathrm{Na}$, number of alleles; Ta, PCR annealing temperature; HO, observed heterozygosity; $\mathrm{HE}$,

expected heterozygosity. 
Mastercycler Personal thermocycler (Eppendorf) with the following cycle program: a first denaturation step at $94^{\circ} \mathrm{C}$ for $5 \mathrm{~min}$, followed by 30 cycles of $94^{\circ} \mathrm{C}$ for $30 \mathrm{~s}, 55-65^{\circ} \mathrm{C}$ for $45 \mathrm{~s}$, and $72^{\circ} \mathrm{C}$ for $45 \mathrm{~s}$, plus 8 more cycles of $94^{\circ} \mathrm{C}$ for $30 \mathrm{~s}, 53^{\circ} \mathrm{C}$ for $45 \mathrm{~s}$, and a $72^{\circ} \mathrm{C}$ for $45 \mathrm{~s}$, and a final extension step at $72^{\circ} \mathrm{C}$ for 10 min. A negative control, consisting of all the reaction components except template DNA, was also included to monitor any possible contamination. Reaction products $(3 \mu \mathrm{L})$ were first subjected to $1 \%$ agarose gel electrophoresis for 45 minutes $(100 \mathrm{~V} / 150 \mathrm{~A})$ in order to verify the amplification efficiency. Four micro liters of the PCR products were further diluted in 26 $\mu \mathrm{L}$ of water. After dilution of the PCR products, 2 $\mu \mathrm{L}$ were mixed with $7.75 \mu \mathrm{L}$ of $0.1 \%$ Tween 20 and $0.25 \mu \mathrm{L}$ of ET-ROX. Samples were denatured at $95^{\circ} \mathrm{C}$ for 3 minutes and submitted to electrophoresis for 51 minutes at $10 \mathrm{kV}$ using a 96 plate of the capillarity nucleotide sequencer MegaBACE1000 (GE Healthcare Life Sciences). Allele sizes were estimated using a DNA marker (ET-550R - GE Healthcare Life Sciences), and the genotyping data, referring to the definition of the allele's peaks, were obtained by the computer program MegaBACE Fragment Profile v 1.0 (GE Healthcare Life Sciences).

\section{STATISTICAL ANALYSES}

Allele frequency, number of alleles per locus, observed $\left(H_{O}\right)$ and expected $\left(H_{E}\right)$ heterozigosity, deviation from Hardy-Weinberg equilibrium, and linkage disequilibrium (Fisher test) were evaluated using Excel Microsatellite Toolkit and the computer program GenePop version 4.0.6 (Rousset, 2008).

\section{RESULTS AND DISCUSSION}

Five microsatellite primer sets were selected as they revealed polymorphic loci in a previous analysis using DNA samples of one male and one female of $C$. japonica that were randomly selected from a domesticated population from Japan (Kayang et al., 2000). In the present study, an initial test was performed using DNA samples of one bird triplet, composed by a single female and two males (F15, M29 and M30), and of its generated embryos on a PCR approach using non-labeled primers and further genotyping through PAGE. Although the PCR conditions initially followed the protocol described by Kayang et al. (2000), several changes were made in order to achieve better amplification results (see present methods description).
In every case, allele sizes were similar to those described by Kayang et al. (2000) in their original report. The primers sets for the GUJ0006 and GUJ0037 loci generated alleles with very diverse sizes in the female and two males analyzed, which easily allowed the correct identification of each animal genotype (Figure 1). It was also possible to determine all offspring genotypes by the use of the GUJ0006 marker as well as their paternity. The determined genotypes of the analyzed individuals and the inferred paternity of the embryos using data for the GUJ0006 and GUJ0037 loci are presented in Table 2. The primers for the GUJ0001 and GUJ0030 loci also allowed the amplification of microsatellite repetitions in the analyzed individuals. However, it was not possible to correctly determine the entire genotype of the birds due to the presence of some diffuse bands. The other selected microsatellite marker (GUJ0025) failed to generate amplification products.

Table 2 - Genotypes of the analyzed adult individuals from one triplet of birds, composed by a female and two males, and of their generated embryos, and the inferred offspring paternity. Data were obtained using two sets of nonlabeled primers in PCR (for the GUJ0006 and GUJ0037 loci) and polyacrylamide electrophoresis genotyping.

Loci

\begin{tabular}{lcccccc} 
& \multicolumn{3}{c}{ GUJ0006 } & \multicolumn{3}{c}{ GUJ0037 } \\
\hline Birds & Allele size & IP & Allele size & IP \\
\hline F15 & 113 & 119 & & 170 & 176 & \\
M29 & 111 & 113 & & 176 & 176 \\
\hline M30 & 119 & 121 & & 176 & 178 \\
\hline E52 & 111 & 113 & M29 & 170 & 176 \\
\hline E53 & 113 & 113 & M29 & 176 & 176 \\
\hline E54 & 111 & 119 & M29 & 176 & 176 \\
\hline E55 & 119 & 119 & M30 & 170 & 176 \\
\hline E56 & 119 & 119 & M30 & 170 & 178 \\
\hline E98 & 113 & 113 & M29 & - & - \\
\hline E102 & 111 & 119 & M29 & 170 & 176 \\
\hline E108 & 113 & 119 & M30 & 176 & 176 \\
\hline
\end{tabular}

F, female; $M$, male; $E$, generated embryo; IP, inferred paternity.

The genotyping failure may be due to primer binding site mutation ("null alleles"), which leads to allele non-amplification, or miscoring of allele banding patterns (Callen et al., 1993; Dakin \& Avise, 2004). Out of these, the most important source of error is probably the incorrect calling of alleles. In particular, the presence of "stutter bands", generated by 


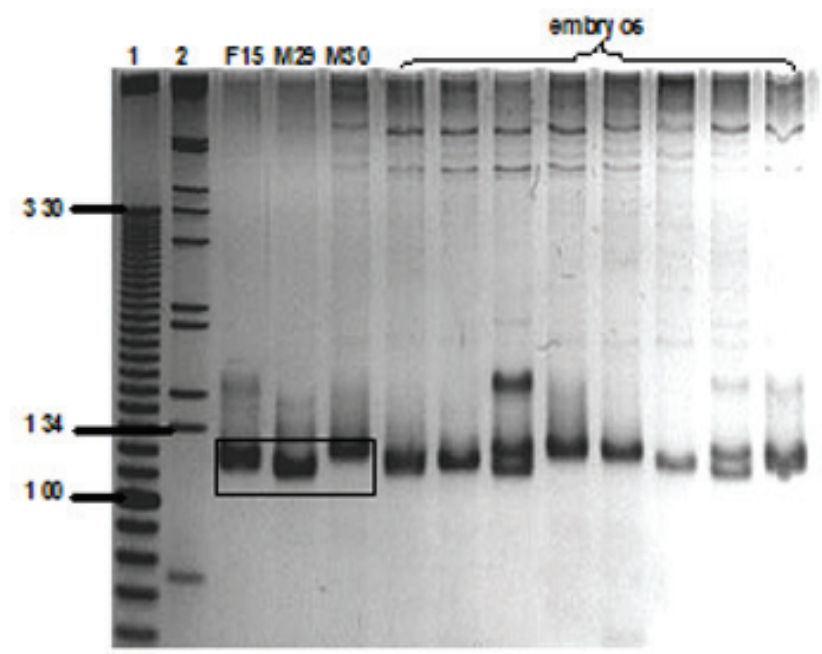

(a)

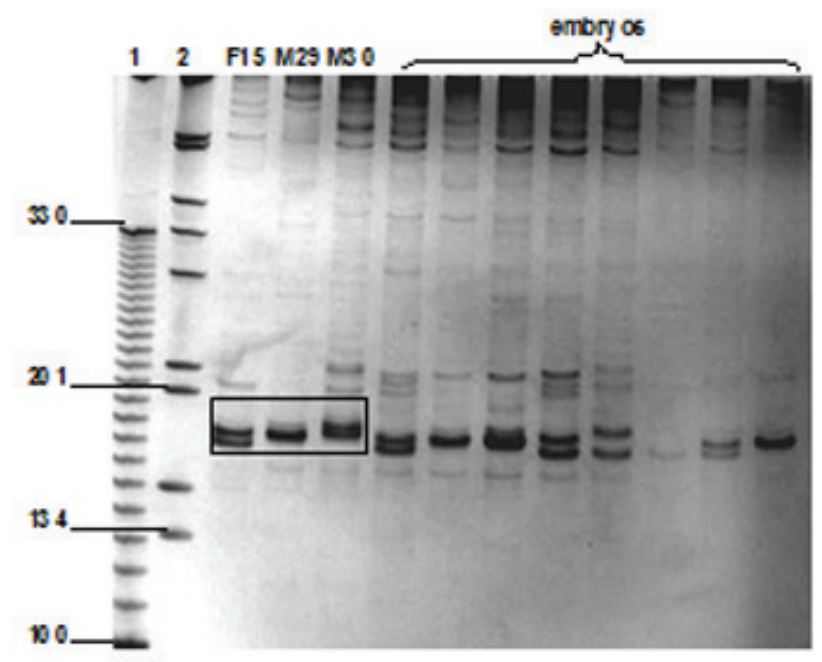

(b)

Figure 1 - Polyacrylamide gel electrophoresis (PAGE) results obtained with the non-labeled primers for the (a) GUJ0006 and (b) GUJ0037 microsatellite loci of Coturnix japonica. (1) 10 bp DNA molecular marker, (2) 1Kb DNA molecular marker, (F) female, (M) males. The box evidences distinct alleles present in the adult female and males that belong to one of the analyzed triplets of birds. The genotypes of the eight generated embryos are also evidenced.

slippage of DNA polymerase during PCR, and also due to polyacrylamide gel analysis, can make it difficult to score alleles reliably, especially when there are large signal intensity differences between alleles and/or the lengths of two alleles in a heterozygous individual differ by only a few nucleotides (Fernando et al., 2001; Johansson et al., 2003). Due to the limited rate of genotyping success in $C$. japonica achieved by the use of common primers in PCR and subsequent PAGE analysis, another microsatellite genotyping test through the use of fluorescent labeled and tailed primers and further automated genotyping was performed.

An initial fluorescent PCR test was performed using the five selected microsatellite primers sets and the DNA samples of one bird triplet (F15, M29 and M30) and its embryos. Amplification products were firstly confirmed by agarose gel electrophoresis and were further submitted to automated analysis. Consistent amplification products were obtained with the use of labeled primers for the GUJ0001, GUJ0006 and GUJ0037 loci. As also observed in PAGE analyses, no amplification products were detected for the GUJ0025 locus and there were no consistent results for the GUJ00030 locus, which led us to eliminate these markers from further analyses. Although the primers sets for the GUJ00025 and GUJ00030 loci were previously successfully amplified in C. japonica (Kayang et al., 2000), these results were obtained in the analysis of only one male and one female randomly sampled from a hatchery colony originated from a wild population in 1970 (Kayang et al., 2000). Even though we cannot discard the possibility of technical amplification problems, the birds analyzed in the present study probably have a different origin and the failure in obtaining PCR results may be due to the high microsatellite mutation rate, which is estimated to occur between $10^{-3}$ and $10^{-5}$ times per locus per generation (e.g. Hancock, 2000). Moreover, recent data have evidenced that the Japanese quail presents a high mutation rate in its overall genome, since several mutations were found to have occurred in different genes in this species during the last 50 years (Tsudzuki, 2008).

A comparison between the results of the PCR with non-labeled primers/PAGE and the PCR with labeled primers/automated genotyping allowed to verify that the allele determination was very similar using the two approaches, considering the presence of 18 additional nucleotides in the alleles obtained by the use of the second methodology due to the forward primer tail (Tables 2 and 3). Minimal differences in the size of the alleles observed when comparing the two employed techniques could be related to the accuracy and/or details of each technique. Despite both methodologies lead to the assumption of homozygous or heterozygous individuals and did not influence the parentage analysis, the use of labeled primers/automated genotyping lead to more robust results.

Although allele determination problems still remain when genotyping is automated, including the presence of stuttering or shadow bands (a leading ladder of minor products preceding the primary allele peak), which leads to difficulties in allele calling, particularly when analyzing dinucleotide repeats on heterozygous individuals with two alleles of close sizes (Hall et al., 
Table 3 - Genotypes of the analyzed adult individuals from ten bird triplets, each composed by a female and two males, and of their respective generated embryos, and the inferred offspring paternity. Data were obtained using three sets of primers, including a fluorescent labeled primer, in PCR (for the GUJ0001, GUJ0006 and GUJ0037 loci) and automated genotyping. Allele incompatibilities between the female known parent and its offspring for the GUJ001 locus, which may reflect the presence of null alleles, appear in bold. Parentage incompatibilities related to the GUJ0037 locus are also evidenced in bold.

\begin{tabular}{|c|c|c|c|c|c|c|c|c|c|c|}
\hline \multicolumn{11}{|c|}{ Loci } \\
\hline \multirow{2}{*}{ Animal } & \multicolumn{3}{|c|}{ GUJ0001 } & \multicolumn{3}{|c|}{ GUJ0006 } & \multicolumn{3}{|c|}{ GUJ0037 } & \multirow{2}{*}{ Paternity assignment } \\
\hline & & & IP & & & IP & & & IP & \\
\hline F04 & 253 & 253 & & 133 & 141 & & 190 & 200 & & \\
\hline M07 & 249 & 255 & & 133 & 137 & & 194 & 206 & & \\
\hline M08 & 249 & 249 & & 129 & 137 & & 198 & 202 & & \\
\hline E05 & 249 & 249 & & 133 & 137 & & 198 & 200 & M08 & M08 \\
\hline E07 & 249 & 253 & & 133 & 137 & & 198 & 200 & M08 & M08 \\
\hline E08 & 249 & 249 & & 133 & 141 & M07 & 200 & 206 & M07 & M07 \\
\hline E11 & 249 & 253 & & 129 & 133 & M08 & 190 & 202 & M08 & M08 \\
\hline E17 & 253 & 255 & M07 & - & - & & 190 & 194 & M07 & M07 \\
\hline E33 & 249 & 249 & & 129 & 133 & M08 & 190 & 202 & M08 & M08 \\
\hline E34 & 253 & 255 & M07 & 133 & 141 & M07 & 194 & 200 & M07 & M07 \\
\hline E121 & 249 & 249 & & 137 & 141 & & 198 & 200 & M08 & M08 \\
\hline E123 & 249 & 253 & & 129 & 141 & M08 & 198 & 200 & M08 & M08 \\
\hline F06 & 253 & 253 & & 131 & 141 & & 204 & 206 & & \\
\hline M11 & 251 & 251 & & 129 & 137 & & 200 & 200 & & \\
\hline M12 & 251 & 255 & & 133 & 139 & & 200 & 204 & & \\
\hline E65 & 251 & 253 & & 129 & 141 & M11 & 200 & 206 & & M11 \\
\hline E66 & 253 & 253 & & 133 & 141 & M12 & 200 & 206 & & M12 \\
\hline E67 & 251 & 251 & & 129 & 131 & M11 & 194 & 206 & M11 & M11 \\
\hline E68 & 251 & 253 & & 129 & 131 & M11 & 194 & 204 & M11 & M11 \\
\hline E69 & 251 & 253 & & 137 & 141 & M11 & 194 & 204 & M11 & M11 \\
\hline E70 & 251 & 253 & & 133 & 141 & M12 & & & & M12 \\
\hline E124 & 251 & 255 & M12 & 133 & 141 & M12 & 204 & 204 & M12 & M12 \\
\hline E126 & 251 & 251 & & 129 & 131 & M11 & 200 & 204 & & M11 \\
\hline E127 & 253 & 255 & M12 & 139 & 141 & M12 & 204 & 206 & M12 & M12 \\
\hline F08 & 251 & 253 & & 137 & 141 & & 194 & 200 & & \\
\hline M15 & 249 & 251 & & 139 & 139 & & 200 & 200 & & \\
\hline M16 & 249 & 255 & & 133 & 137 & & 204 & 204 & & \\
\hline E24 & 251 & 251 & M15 & 139 & 141 & M15 & 200 & 200 & M15 & M15 \\
\hline E110 & & & & & & & 200 & 204 & M16 & M16 \\
\hline E111 & 251 & 255 & M16 & 133 & 137 & M16 & 194 & 204 & M16 & M16 \\
\hline E116 & 249 & 253 & & 137 & 141 & M16 & 200 & 204 & M16 & M16 \\
\hline E119 & 249 & 251 & & 133 & 141 & M16 & & & & M16 \\
\hline F09 & 255 & 255 & & 127 & 131 & & 200 & 204 & & \\
\hline M17 & 249 & 255 & & 129 & 129 & & 202 & 206 & & \\
\hline M18 & & & & 127 & 127 & & 200 & 200 & & \\
\hline E25 & 255 & 255 & & 127 & 127 & M18 & 200 & 200 & M18 & M18 \\
\hline E26 & 255 & 255 & & 127 & 131 & M18 & 200 & 200 & M18 & M18 \\
\hline E37 & 253 & 255 & & 127 & 127 & M18 & 200 & 200 & M18 & M18 \\
\hline E38 & 253 & 255 & & 127 & 131 & M18 & 200 & 204 & M18 & M18 \\
\hline F12 & 251 & 255 & & 131 & 133 & & 200 & 200 & & \\
\hline M23 & 253 & 253 & & 129 & 141 & & 200 & 206 & & \\
\hline M24 & 255 & 255 & & 133 & 141 & & 204 & 204 & & \\
\hline E41 & 251 & 253 & M23 & 131 & 141 & & 200 & 200 & M23 & M23 \\
\hline E42 & 253 & 255 & M23 & 129 & 131 & M23 & 200 & 200 & M23 & M23 \\
\hline E43 & 251 & 255 & M24 & 133 & 133 & M24 & 200 & 204 & M24 & M24 \\
\hline
\end{tabular}




\begin{tabular}{|c|c|c|c|c|c|c|c|c|c|c|}
\hline \multicolumn{11}{|c|}{ Loci } \\
\hline \multirow{2}{*}{ Animal } & \multicolumn{3}{|c|}{ GUJ0001 } & \multicolumn{3}{|c|}{ GUJ0006 } & \multicolumn{3}{|c|}{ GUJ0037 } & \multirow{2}{*}{ Paternity assignment } \\
\hline & & & IP & & & IP & & & IP & \\
\hline E44 & 251 & 253 & M23 & 133 & 141 & & 200 & 200 & $\mathrm{M} 23$ & M23 \\
\hline E45 & & & & & & & 200 & 204 & M24 & M24 \\
\hline E46 & 251 & 253 & $\mathrm{M} 23$ & 129 & 131 & $\mathrm{M} 23$ & 200 & 200 & $\mathrm{M} 23$ & $\mathrm{M} 23$ \\
\hline E63 & 251 & 253 & M23 & 131 & 141 & & 200 & 206 & M23 & M23 \\
\hline E64 & 251 & 255 & M24 & 133 & 141 & & 200 & 204 & M24 & M24 \\
\hline E109 & & & & 129 & 131 & M23 & 200 & 200 & M23 & M23 \\
\hline E112 & 251 & 255 & M24 & 133 & 141 & & 200 & 204 & M24 & M24 \\
\hline E122 & 255 & 255 & M24 & 133 & 133 & M24 & 200 & 204 & M24 & M24 \\
\hline F13 & 251 & 253 & & 133 & 139 & & 190 & 200 & & \\
\hline M25 & 255 & 255 & & 131 & 141 & & 200 & 204 & & \\
\hline M26 & 251 & 255 & & 131 & 137 & & 190 & 200 & & \\
\hline E47 & 251 & 255 & & 139 & 141 & M25 & 190 & 200 & & M25 \\
\hline E48 & 251 & 255 & & 131 & 139 & & 190 & 204 & M25 & M25 \\
\hline E49 & 251 & 255 & & 131 & 133 & M25 & 190 & 200 & & M25 \\
\hline E50 & 251 & 255 & & 139 & 141 & M25 & 190 & 200 & & M25 \\
\hline E51 & 251 & 255 & & 131 & 139 & & 200 & 200 & & \\
\hline F14 & 255 & 255 & & 141 & 141 & & 204 & 204 & & \\
\hline M27 & 249 & 255 & & 139 & 139 & & 198 & 204 & & \\
\hline M28 & 247 & 249 & & 127 & 127 & & 194 & 200 & & \\
\hline E77 & 255 & 255 & M27 & 139 & 141 & M27 & 204 & 204 & M27 & M27 \\
\hline E78 & 255 & 255 & M27 & 139 & 141 & M27 & 198 & 202 & M27 & M27 \\
\hline E79 & 255 & 255 & M27 & 139 & 141 & M27 & 204 & 204 & M27 & M27 \\
\hline E80 & 255 & 255 & $\mathrm{M} 27$ & 139 & 141 & M27 & 204 & 204 & M27 & M27 \\
\hline E81 & 255 & 255 & M27 & 139 & 141 & M27 & 196 & 204 & & M27 \\
\hline E82 & 249 & 255 & & & & & 204 & 204 & M27 & M27 \\
\hline F15 & 255 & 255 & & 133 & 137 & & 194 & 200 & & \\
\hline M29 & 255 & 255 & & 129 & 133 & & 200 & 200 & & \\
\hline M30 & 251 & 255 & & 137 & 141 & & 194 & 200 & & \\
\hline E52 & 255 & 255 & & 129 & 133 & M29 & 194 & 202 & & M29 \\
\hline E53 & 255 & 255 & & 133 & 133 & M29 & 194 & 206 & & M29 \\
\hline E54 & 255 & 255 & & 129 & 137 & M29 & 200 & 200 & & M29 \\
\hline E55 & 251 & 255 & & 137 & 141 & M30 & 200 & 200 & & M30 \\
\hline E56 & 255 & 255 & & 137 & 137 & M30 & 200 & 200 & & M30 \\
\hline E98 & 255 & 255 & & 133 & 133 & M29 & 194 & 200 & & M29 \\
\hline E102 & 255 & 255 & & 129 & 137 & M29 & 194 & 200 & & M29 \\
\hline E108 & 255 & 255 & & 133 & 137 & & 200 & 202 & & \\
\hline F16 & 249 & 251 & & 131 & 137 & & 200 & 202 & & \\
\hline M31 & 251 & 255 & & & & & 200 & 200 & & \\
\hline M32 & 249 & 249 & & 133 & 141 & & 200 & 200 & & \\
\hline E57 & 251 & 251 & M31 & 137 & 139 & & 200 & 200 & & M31 \\
\hline E114 & 249 & 251 & M31 & 133 & 133 & & 194 & 200 & & M31 \\
\hline E117 & 249 & 249 & M32 & 131 & 133 & & 200 & 202 & & M32 \\
\hline F17 & 253 & 255 & & 135 & 137 & & 200 & 204 & & \\
\hline M33 & 251 & 253 & & 137 & 139 & & 194 & 206 & & \\
\hline M34 & 253 & 253 & & 137 & 141 & & 200 & 204 & & \\
\hline E83 & 253 & 255 & & 137 & 137 & & 200 & 206 & M33 & M33 \\
\hline E105 & 253 & 253 & & 135 & 139 & M33 & 202 & 206 & M33 & M33 \\
\hline E106 & 253 & 255 & & 137 & 137 & & 200 & 204 & M34 & M34 \\
\hline E107 & 253 & 255 & & 137 & 137 & & 204 & 204 & M34 & M34 \\
\hline
\end{tabular}

F, female; $M$, male; E, generated embryo; IP, inferred paternity. 
1996), it is an accurate technique, specially due to the minor handling of samples and to computer software efficiency. Moreover, the strong detection sensitivity of the fluorescent labeled primers produces good results even with minute amounts or even old/degraded template DNA (Schuelke, 2000).

Therefore, we performed additional analyses for the GUJ0001, GUJ0006 and GUJ0037 loci using the automated genotyping approach. Ten bird triplets (each composed by a female and two males) and their respective embryos were successfully analyzed and polymorphism level was assessed by typing 94 individuals of C. japonica (30 adults and 64 embryos) (Table 3). In general, the automated genotyping results were consistent and the alleles were easily determined (Figure 2). All the three analyzed loci were polymorphic ( $\mathrm{Na}=$ 5-8, mean $H_{E}=0.75$ ) and no locus was found to deviate significantly from the Hardy-Weinberg equilibrium or showed any evidence of linkage disequilibrium ( $p>$ 0.05) (Table 1). However, the GUJ0001 locus showed evidence of a slight heterozygote deficiency and some incompatibilities were observed between the female known parent and its offspring that invariably involved homozygous genotypes (Table 3 ). These results may indicate the presence of null alleles, generally a typical result from polymorphism due to point mutations or insertions/deletions in the flanking sequence of the locus, such that some alleles lack a functional PCR priming site (Callen et al., 1993; Ishibashi et al., 1996; Jones \& Ardren, 2003). Parentage incompatibility was also observed for some embryos using the GUJ0037 marker (Table 3), a finding that seems to be related to errors on the genotyping analysis and not to "allelic dropout". Nevertheless, it was possible to infer the male's paternity for $96.87 \%$ of the generated embryos using combined data of the three analyzed microsatellite loci (Table 3).

The genetic parentage inferences also allowed to evidence no significant difference in the contributions of the two potential male parents of $C$. japonica to the offspring $(p=0.755)$. Although these data were observed in an experimental design, they lead to the assumption of a potential occurrence of a polyandric mating system in this species, as already evidenced for the European quail (C. coturnix) through a multilocus DNA fingerprinting analysis (Rodriguez-Teijeiro et al., 2003).

The genetic paternity results in C. japonica were correlated to sperm and behavioral analyses performed in the same ten bird triplets. Combined data evidenced
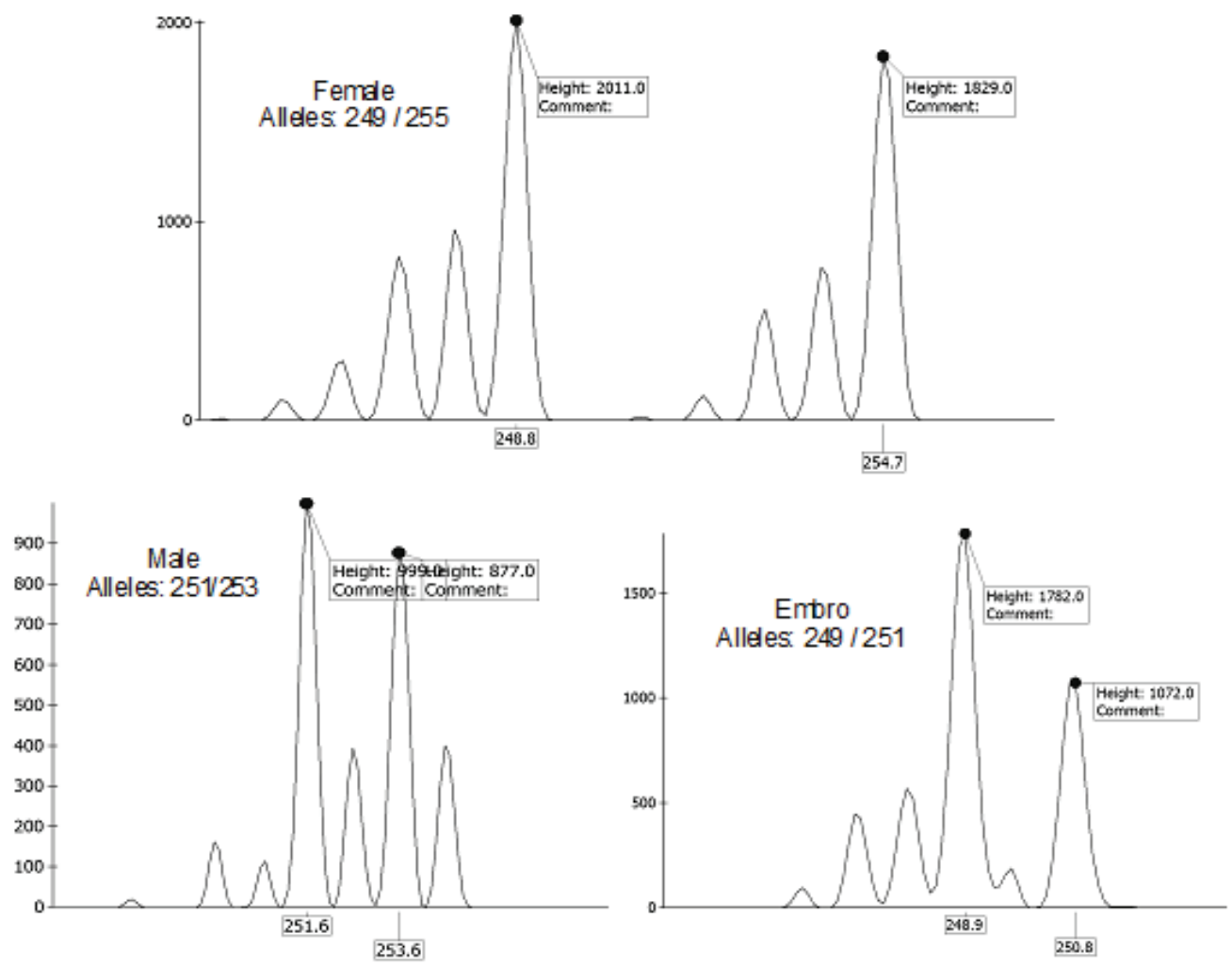

Figure 2 - Examples of electropherograms generated by automated genotyping. Fragment size in base pairs is shown on the horizontal axis and fluorescence is evidenced in the vertical axis. 
no sperm selection by females merely based on sperm quality (concentration, vitality, or motility) and that the offspring paternity was also not influenced by the number of copulas by each male or by the male that performed the first or the last copulation (Gomes 2009). This shows that, apparently, a last-male mating advantage, in which spermatozoa from the last male to mate within a brief period results in the fertilization of most eggs, a mechanisms that has been described in several bird species, specially those with SSTs (Sperm Storage Tubules) (Birkhead \& Moller, 1998), does not occur in C. japonica.

The occurrence of a potential polyandric mating system in Japanese quails was reinforced by several features that may predispose these birds to mating changes, such as lack of parental care by males and a sex ratio strongly biased in favor of males throughout the breeding season (Rodrigues-Teijeiro et al., 2003), which is also reflected in genetic polygamy. Moreover, as mating in Japanese quail frequently fails to result in eggs fertilization (Adkins-Regan, 1995) and female quails cannot use the physical act of copulation to determine that their eggs have been fertilized, copulations from additional males could be a sexual strategy to obtain some advantages. These not only include a higher probability of egg fertilization, but also comprise genetic benefits, such as the acquisition of "good genes" and an increase in genetic diversity of clutches (e.g. Evans \& Simmons, 2008).

In conclusion, despite the use of a reduced set of microsatellite primers in the present study, it was possible to determine the paternity of most of the analyzed embryos of Coturnix japonica when using combined data of three polymorphic loci, leading to the assumption of a potential polyandric mating system in this species, in which no advantage mechanism of last-male sperm precedence seems to occur. More consistent data could be achieved with the redesign of the PCR primers suspected of producing null alleles in an attempt to recover normal inheritance at the GUJ0001 locus. A recent model for detecting multiple mating in vertebrates evidenced that, if two males (or females) contribute with equal fertilization success, then only ten offspring and one microsatellite locus with seven alleles seem to be required to ensure that $80 \%$ of multiple mated broods are detected. Ninety-five per cent of multiple mated broods can be detected through the analysis of ten offspring and five loci with four alleles (Neff \& Pitcher, 2002). The parentage test reported here seems to fit this proposed model and could be a valuable tool for documenting paternity patterns in C. japonica. These data can be useful to support behavioral analyses related to fertility success and also to support selective breeding programs of the species.

\section{ACKNOWLEDGEMENTS}

The authors thank Granja Suzuki (São Paulo, Brazil) for providing us the Japanese quails, Dr. Silvia Mitiko Nishida for her assistance in the maintenance of the birds at the vivarium of the Biosciences Institute, São Paulo State University, Brazil, and Fernando Fonseca Pereira de Paula for his helpful assistance in the automated genotyping. This work was financially supported by CNPq (Conselho Nacional de Desenvolvimento Científico e Tecnológico). The first author was supported by a fellowship from FAPESP (Fundação de Amparo à Pesquisa do Estado de São Paulo).

\section{REFERENCES}

Adkins-Regan E. Predictors of fertilization in the Japanese quail Coturnix japonica. Animal Behaviour 1995;50:1405-1415

Alcaide M, Negro JJ, Serrano D, Tella JL, Rodríguez C. Extra-pair paternity in the Lesser Kestrel Falco naumanni: a re-evaluation using microsatellite markers. Ibis 2005;147:608-611.

Bartfai R, Egedi S, Yue G.H, Kovacs B, Urbanyi B, Tamas G, Horvath L , Orban L. Genetic analysis of two common carp broodstocks by RAPD and microsatellite markers. Aquaculture 2003;219:157-167.

Birkhead TR, Moller AP. Sperm competition and sexual selection. London / Academic Press; 1998

Callen DF, Thompson AD, Sehn Y. Incidence and origin of 'null' alleles in the $(A C) n$ microsatellite markers. American Journal of Human Genetics $1993 ; 52: 922-927$

Dakin EE, Avise JC. Microsatellite null alleles in parentage analysis. Heredity 2004;93:504-509

Delville Y, Sulon J, Balthazart J. Diurnal variations of sexual receptivity in the female Japanese quail (Coturnix coturnix japonica). Hormones and Behaviour 1986;20:13-33

Evans JP, Simmons LW. The genetic basis of traits regulating sperm competition and polyandry: can selection favor the evolution of goodand sexy-sperm? Genetica 2008;134:5-19.

Fernando P, Evans BJ, Morales JC, Melnici DJ. Electrophoresis artifacts a previously unrecognized cause of error in microsatellite analysis. Molecular Ecology Notes 2001;1:325-328.

Fossoy F, Johnsen A, Lifield JT. Evidence of obligate female promiscuity in a socially monogamous passerine. Behaviour, Ecology and Sociobiology 2006;60:255-259

Gholizadeh M, Mianji R. Use of microsatellite markers in poultry research. International Journal of Poultry Science 2007;6:145-153.

Gomes ML. Determinação das relações entre o comportamento de acasalamento e o sucesso reprodutivo na codorna japonesa (Coturnix japonica): uma abordagem multidisciplinar através de análises etológicas, espermáticas e genéticas [dissertação]. Botucatu (SP): Universidade Estadual Paulista; 2011. 
ML Gomes, T Hatanaka, WN de Campos, AP Wasko

Griffith SC, Owens IPF, Thuman KA. Extra pair paternity in birds: a review of interespecific variation and adaptive function. Molecular Ecology 2002; 11:2195-2212

Hall JM, LeDuc CA, Watson AR, Roter AH. An approach to high-throughput genotyping. Genome Research 1996;6:781-790.

Hancock R. A new look at the nuclear matrix. Chromosoma 2000;109:219225.

Ishibashi Y, Saitoh T, Abe S, Yoshida C. Null microsatellite alleles due to nucleotide sequence variation in the grey-sided vole Clethrionomys rufocanus. Molecular Ecology 1996;5:589-590.

Jehle R, Arntzen JW. Microsatellite markers in Amphibian conservation genetics: A review. Herpetology Journal 2002;12:1-9.

Johansson A, Karlsson P, Gyllensten U. A novel method for automatic genotyping of microsatellites markers based on parametric pattern recognition. Human Genetics 2003;113:316-324.

Jones AG, Ardren WR. Methods of parentage analysis in natural populations. Molecular Ecology 2003; 12:2511-2523.

Kayang BB, Inoue-Murayama M, Nomura A, Kimura K, Takahashi H, Mizutani M, Ito S. Fifty microsatellite markers for Japanese quail. Journal of Heredity 2000;91:502-505.

Kayang BB, Vignal A, Inoue-Murayama M, Miwa M, Monvoisin JL, Ito $S$, Minvielle F. A first-generation microsatellite linkage map of the Japanese quail. Animal Genetics 2004; 35:195-200.

Kikuchi S, Fujima D, Sasazaki S, Tsuji S, Mizutani M, Fujiwara A, Mannen $\mathrm{H}$. Construction of a genetic linkage map of Japanese quail (Coturnix japonica) based on AFLP and microsatellite markers. International Society of Animal Genetics 2005;36: 227-231.

Kovach JK. The behaviour of Japanese quail: review of literature from a bioethological perspective. Applied Animal Ethology 1974;1:77-102.

Marle-Koster EV, Nel LH. Genetic markers and their application in livestock breeding in South Africa: A review. South African Journal of Animal Science 2003;33:1-10.

Masters BS, Hicks BG, Johnson LS, Erb LA. Genotype and extra-pair paternity in the house wren: a rare-male effect. Proceedings of the Royal Society of London Series B-Biological Sciences 2003; 270:1393-1397.

Matthews RN, Domjan M, Ramsey M, Crews D. Learning effects on sperm competition and reproductive fitness. Psychology Science 2007;18:758762.

Neff BD, Pitcher TE. Assessing the statistical power of genetic analyses to detect multiple mating in fishes. Journal of Fish Biology 2002;61:739-750.

Pang SWY, Ritland C, Carlson JE, Cheng KM. Japanese quail microsatellite loci amplified with chicken-specific primers. Animal Genetics 1999;30:195

Pisenti JM, Delany ME, Taylor RL, Abbott UK. Avian genetic diversity: domesticated species. Davis: University of California, Division of Agriculture and Natural Resources, Genetic Resources Conservation Program; 1999.

Powierska-Czarny J, Miscicka-Sliwaka D, Czarny J, Grzybowski T, Wozniak M, Drewa G, Czechowicz W, Sir J. Analysis of microsatellite instability and loss of heterozygosity in breast cancer with the use of a well characterized multiplex system. Acta Biochimica Polonica 2003; 50:1195-1203.

Primmer CR, Raudsepp T, Chowdhary BP, Moller AR, Ellegren H. Low frequency of microsatellites in the avian genome. Genome Research $1997 ; 7: 471-482$
Assessing Paternity in Japanese Quails (Coturnix Japonica) Using Microsatellite Markers - Inferences for Its Mating System and Reproductive Success

Rodrigues-Teijeiro JD, Puigcerver M, Gallego S, Cordero PJ, Parkin DT. Pair bonding and multiple paternity in the polygamous Common Quail Coturnix coturnix. Ethology 2003;109:291-302.

Rousset F. GENEPOP '007: a complete reimplementation of the GENEPOP software for Windows and Linux. Molecular Ecology Research 2008;8:103-106.

Sambrook J, Russel DW. Molecular cloning - a laboratory manual. $3^{\text {rd }}$ ed. New York: Cold Spring Harbor Laboratory Press; 2001.

Schulelke M. An economic method of the fluorescent labeling of PCR fragments. Nature Biotechnology 2000;18:233-234.

SEBRAE Ponto de partida para início de negócio: saiba como montar criação de codorna. Belo Horizonte: SEBRAE; 2008

Shurtliff QR, Pearse DE, Rogers DS. Parentage analysis of the canyon mouse (Peromyscus crinitus): evidence for multiple paternity. Journal of Mammalogy 2005;86:531-540

Tsudzuki M. Mutations of Japanese quail (Coturnix japonica) and recent advances of molecular genetics for this species. Journal of Poultry Science 2008;45:159-179.

Webster MS, Reichard L. Use of microsatellites for parentage and kinship analyses in animals. Molecular Evolution: Biochemistry Data, Part B Methods in Enzymology 2005;395:222-238.

White DJ, Galef BG. Affiliative preferences are stable and predicted mate choices in both sexes of Japanese quail, Coturnix japonica. Animal Behaviour 1999;58:863-871

Wolfgang A, Steiner FM, Schlick-Steiner BC. Rapid and cost-effective screening of newly identified microsatellite loci by high-resolution melting analysis. Molecular Genetics and Genomics 2011; 286:225235 